\title{
Alfabetização na pandemia: políticas públicas do estado de Minas Gerais, Brasil, direcionadas à educação nos anos iniciais do ensino fundamental no período de isolamento social
}

A pandemia do novo coronavírus atingiu proporções que ninguém poderia prever e impactou negativamente a maioria dos países do mundo. Além dos mais de 18,1 milhões de casos, já foram contabilizadas mais de 690 mil mortes pela nova doença até 02 de agosto de 2020. No Brasil, essa enfermidade causou uma enorme crise nos órgãos públicos, principalmente nos que oferecem serviços como a saúde e a educação, e fez com que o país necessitasse de medidas emergenciais para a contenção dos problemas. Ainda, em território brasileiro, as unidades federativas gozam de relativa autonomia para gerir os impactos causados pela COVID-19, doença causada pelo novo vírus. A propagação é muito rápida e ocasionada pela infecção po gotículas secretadas pelas pessoas doentes. Desta maneira quase todos os locais do Brasil adotaram o isolamento social como forma de prevenção da disseminação do novo vírus e contorno de um possível colapso dos sistemas estatais. Assim, o distanciamento das pessoas impactou diretamente a prática da educação. No estado de Minas Gerais, o governo lançou o Plano de Estudos Tutorados (PET), o qual apresenta orientações e atividades para os alunos desenvolverem com auxílio dos pais ou responsáveis. Assim, este estudo visa analisar os PETs direcionados aos anos iniciais do ensino fundamental, além de levantar os benefícios e defasagens para a alfabetização constantes no projeto. Trata-se de uma pesquisa qualitativa, analítica e exploratória feita a partir da análise de dados disponíveis no site da Secretaria de Educação de Minas Gerais. Assim, os documentos foram analisados e constatou-se que esse projeto se apresenta interessante no que diz respeito a manutenção das práticas educativas no contexto do isolamento social. Contudo, apresenta problemas no que tange ao acesso dos alunos à internet, a diversidade dos ambientes familiares e à inaptidão, muitas vezes, da maioria das famílias em estabelecer as práticas pedagógicas e eficácia no processo de alfabetização. Por isso, se consider que não se pode exigir que famílias que nunca foram capacitadas para isso saibam como gerir, mesmo que provisoriamente, a educação desses alunos. Ensino que se faz, geralmente, mais complexo por se tratar da questão da alfabetização e que exige manejo adequado para que seja eficiente e duradouro.

Palavras-chave: COVID-19; Pandemia; Políticas públicas; Alfabetização; Educação fundamental de anos iniciais.

\section{Literacy in the pandemic: public policies in the state of Minas Gerais, Brazil, aimed at education in the early years of fundamental education in the period of social isolation}

\begin{abstract}
The pandemic of the new coronavirus has reached proportions that no one could have predicted and has negatively impacted most countries in the world. In addition to the more than 18.1 million cases, more than 690 thousand deaths from the new disease have been recorded by August 2, 2020. In Brazil, this disease has caused a huge crisis in public agencies, especially those that offer services such as health and education, and made the country need emergency measures to contain the problems. Also, in Brazilian territory, the federative units enjoy relative autonomy to manage the impacts caused by COVID-19, a disease caused by the new virus. The spread is very fast and caused by infection by droplets secreted by sick people. In this way, almost all locations in Brazil have adopted social isolation as a way of preventing the spread of the new virus and bypassing a possible collapse of state systems. Thus, the distance from people directly impacted the practice of education. In the state of Minas Gerais, the government launched the Tutored Study Plan (TSP), which presents guidelines and activities for students to develop with the help of parents or guardians. Thus, this study aims to analyze TSPs targeted at the early years of elementary school, in addition to raising the benefits and lags for literacy contained in the project. This is a qualitative, analytical and exploratory research, based on the analysis of data available on the website of the Minas Gerais Department of Education. Thus, the documents were analyzed and it was found that this project is interesting in terms of maintaining educational practices in the context of social isolation. However, it presents problems regarding students' access to the internet, the diversity of family environments and the inability, often, of most families to establish pedagogical practices and effectiveness in the literacy process. For this reason, it is connided that families that have never been trained to do this can not be required to know how to manage, even if provisionally, the education of these students. Teaching that is usually made more complex because it deals with the issue of literacy and that requires adequate management so that it is efficient and lasting.
\end{abstract}

Keywords: COVID-19; Pandemic; Public policy; Literacy; Elementary education of early years.

Topic: Políticas Públicas na Educação

Reviewed anonymously in the process of blind peer
Received: 10/04/2020

Approved: 28/07/2020
Marcos Lorran Paranhos Leão

Universidade de Pernambuco, Brasil

http://lattes.cnpq.br/7449167140800038

http://orcid.org/0000-0002-6259-2430

upeleao@gmail.com

Maria Tereza Damasceno de Oliveira

Universidade Federal de Minas Gerais, Brasil

http://lattes.cnpq.br/5048223818175455

http://orcid.org/0000-0002-9658-4113

mariatereza1998@outlook.com

Sinara de Oliveira Paranhos Leão (iD)

Universidade Vales do Rio Doce, Brasil

http://lattes.cnpq.br/8654845846349484

http://orcid.org/0000-0001-9424-4716

sinara.leao@educacao.mg.gov.br

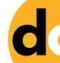

DOI: 10.6008/CBPC2674-6646.2020.002.0004
Referencing this:

LEÃO, M. L. P.; OLIVEIRA, M. T. D.; LEÃO, S. O. P.. Alfabetização na pandemia: políticas públicas do estado de Minas Gerais, Brasil, direcionadas à educação nos anos iniciais do ensino fundamental no período de isolamento social. Justitia Liber, v.2, n.2, p.18-22, 2020. DOI: http://doi.org/10.6008/CBPC2674-6646.2020.002.0004 
Alfabetização na pandemia: políticas públicas do estado de Minas Gerais, Brasil, direcionadas à educação nos anos iniciais do ensino

\section{INTRODUÇÃO}

A Organização Mundial da Saúde declarou, em março de 2020, que a COVID-19 (doença causada pelo novo coronavírus) aumentava o seu status para a mais alta classificação que a progressão de uma doença pode alcançar, pandemia (WHO, 2020). O meio de transmissão dessa enfermidade é, frequentemente, por gotículas espalhadas por uma pessoa infectada no ar ou em superfícies e que, posteriormente, encontram as mucosas de indivíduos saudáveis sendo levadas pelo ar ou pelas mãos das próprias pessoas, após tocarem em um local infectado (MCINTOSH, 2020). Essa nova doença já atingiu mais de 18,1 milhões de pessoas no mundo e causou o óbito de mais de 690 mil delas, 02 de agosto de 2020 (JHU, 2020). Por isso, o isolamento social tem sido amplamente recomendado como a principal arma na diminuição da progressão do contágio (OLIVEIRA et al., 2020).

No Brasil, o Conselho Nacional de Educação (CNE), pertencente ao Ministério da Educação, aprovou diretrizes tanto para a educação básica quanto para a superior durante a pandemia (BRASIL, 2020). O documento autoriza, entre outras coisas, os sistemas de ensino a computar atividades não presenciais para cumprimento de carga horária (BRASIL, 2020).

Em 22 de abril de 2020, o estado de Minas Gerais, por meio de resolução oficial ( $n^{\circ} 4310 / 2020$ ), publicada no site da secretaria de educação, regulamentou, no âmbito das escolas estaduais de ensino de Minas Gerais, as normas para a oferta de regime especial de atividades não presenciais, durante o período de emergência e de implementação das medidas de prevenção ao contágio e enfrentamento da pandemia de doença infecciosa viral respiratória causada pelo agente Coronavírus (COVID- 19), para cumprimento da carga horária mínima exigida (BRASIL, 2020b). Em março de 2020, o governo de Minas declarou, por meio do Decreto № 113, situação de emergência no estado em decorrência da pandemia do coronavírus (MINAS GERAIS, 2020). Depois, em um período de menos de um mês, foram publicados uma série de deliberações culminando na determinação da volta às atividades, em regime de teletrabalho, dos servidores do estado, incluídos os profissionais da educação. Desde então, foram disponibilizadas algumas ferramentas de trabalho online, como a plataforma online Estude em Casa, que serve tanto para os servidores, quanto para os alunos da rede estadual de educação (REANP, 2020).

Dentro da Estude em Casa, o discente e os responsáveis encontram algumas ferramentas, como o Plano de Estudo Tutorado (PET), que Ihe são úteis para auxiliar e guiar os estudos em domicílio. O PET é um modelo instrucional, que além de trazer o conteúdo, direciona o aluno a como começar e quando e como realizar as atividades (REANP, 2020).

Além disso, é válido ressaltar que Minas Gerais tinha, em 2019, mais de 1 milhão e 337 mil estudantes nos anos iniciais do ensino fundamental (INEP, 2020). Assim, devido à importância desse contingente e de todos os processos educacionais nos quais esses alunos estão envolvidos, como a alfabetização e formação de conhecimentos básicos, este trabalho torna-se de grande relevância ao analisar a política que atinge esses alunos no período de isolamento social. Por isso, este estudo objetiva analisar os PETs do Ensino Fundamental (PETs: EF): Anos Iniciais, disponíveis para esses discentes e levantar, quando oportuno, seus auxílios e 
defasagens.

\section{METODOLOGIA}

Para a confecção desta pesquisa foram analisados os documentos disponibilizados pelo governo do estado de Minas Gerais sobre dos planos direcionados aos discentes dos anos iniciais do ensino fundamental. A metodologia empregada para a realização deste trabalho baseia-se em uma pesquisa qualitativa de caráter exploratório e analítico, feita a partir da investigação documental da política pública de estudos tutorados para estudantes do ensino básico: anos iniciais de Minas Gerais, Brasil, disponível no site da Secretaria de Educação de Minas Gerais, na plataforma Estude em Casa ${ }^{1}$. Ainda, por se tratar de uma pesquisa que utiliza informações de acesso público, nos termos da Lei n 12.527 , de 18 de novembro de 2011, e revisão de textos científicos, não precisa de prévia autorização em comitê de ética, respaldada pelo parágrafo único do Art $1^{\circ}$ da resolução 510/2016, resolvida pela Comissão Nacional de Ética em Pesquisa - CONEP, do Conselho Nacional de Saúde - CNS (BRASIL, 2016).

\section{DISCUSSÃO TEÓRICA}

Após a análise dos PETs: EF referente aos anos iniciais, evidenciou-se que eles apresentam orientações para os pais ou responsáveis e para os estudantes, bem como textos, ilustrações, atividades que envolvem leitura e interpretação e exercícios lúdicos como pinturas e músicas. Ainda, todos os documentos apresentam as disciplinas referentes a cada ano de ensino, e as orientações são para que os alunos, com auxílio da família, façam os PETs e posteriormente os apresentem para correção dos professores (REANP, 2020).

Ainda, esses documentos são divididos entre ensino regular, ensino integral, modalidades especiais e modalidades especiais: educação indígena. Eles são separados em vários módulos e apresentam todas as matérias letivas, do respectivo ano, separadas em semanas e tópicos de conteúdo. Além disso, são divididos por ano de ensino (REANP, 2020).

Quanto ao conteúdo dos PETs: EF (anos iniciais), esses planos variam com relação a ano do discente e os do ensino regular e integral vão se tornando mais complexos no decorrer dos anos. Esses, apresentam desde atividades com separação silábica, muitos textos e imagens, no primeiro ano, a atividades mais complexas como interpretação textual e multiplicação e divisão de números racionais, no quinto ano. Relacionado aos documentos direcionados à educação especial, as atividades acompanham a modalidade regular; contudo, contam com adaptações necessárias ao entendimento e progressão de muitos estudantes especiais. Por fim, os direcionados à educação indígena são escritos em língua nativa, apresentam atividades de alfabetização, imagens e textos; ainda, são divididos em dois volumes (REANP, 2020).

É imprescindível destacar que a educação de anos iniciais necessita de contato físico, interação, brincadeira, olho no olho, toque e que, assim, não se pode pensar numa educação a distância que faça

\footnotetext{
${ }^{1}$ https://estudeemcasa.educacao.mg.gov.br/inicio 
Alfabetização na pandemia: políticas públicas do estado de Minas Gerais, Brasil, direcionadas à educação nos anos iniciais do ensino

cumprir o papel do desenvolvimento nessa etapa da Educação Básica (LORZING et al., 2020). Nesse âmbito, as Tecnologias da Informação e Comunicação (TICS) surgem como uma ferramenta de mitigação dos dados da distância entre professor e aluno (CURY, 2020). Contudo, se por um lado o uso das tecnologias é fundamental para essa aproximação estre profissionais e alunos, por outro, professores sentem-se, muitas vezes, impotentes e despreparados para lidar com essa mudança (RODRIGUES, 2020; CURY, 2020). Por isso, muitos municípios mineiros e o próprio Estado estão investindo em capacitação docente para enfretamento a essa questão (CURY, 2020; RIBEIRO et al., 2020). Ainda, além desse problema, 21\% dos domicílios em Minas Gerais não tinham rede de internet em 2018 (IBGE, 2018), dificultando que alguns alunos acessem os planos e os professores.

É importante ressaltar, ainda, que algumas residências não apresentam um ambiente minimamente eficaz aos estudos e, dessa maneira, o processo da educação inicial será desigual entre os alunos (RESENDE et al., 2020). Vários fatores podem servir como distração para os discentes nesses locais, processo bastante agravado se eles apresentarem algum déficit de atenção (BARRETO et al., 2020). Ainda, muitos alunos não dispõem de um espaço adequado para o desenvolvimento do processo de ensino e aprendizagem nos lares (BARRETO et al., 2020).

Por fim, essa problemática permeia a imposição para a família da execução do processo de alfabetização, que não the pertence nem a cabe e que, é feito, frequentemente, de modo improvisado, muitas vezes, sem o acompanhamento dos profissionais da educação (COUTINHO et al., 2020). Isso evidencia uma prática que pode, por vezes, fracassar, tanto no que tange as habilidades da família em manejar essas tarefas quanto no processo de aprendizagem do estudante, principalmente aos que apresentam alguma deficiência.

\section{CONCLUSÕES}

Portanto, os PETs: EF (anos iniciais) apresentam-se com planos, determinações e direcionamentos interessantes. Contudo, geralmente, mesmo com as orientações, as famílias têm uma dificuldade multifatorial para coloca-los em prática. Ainda, é evidenciado que esses planos exigem que as famílias assumam uma tarefa que não é delas e que não foram preparadas para exercer. $\mathrm{O}$ acompanhamento de um profissional qualificado para gerir esse processo de alfabetização é essencial, sem isso, o estudante fica à mercê de diferentes fatores que influenciam a prática pedagógica.

Ainda, consideramos que apesar das TICs se apresentarem como ferramentas com inovações consideráveis e que têm um importante papel no contexto atual de pandemia, não podem ter seu papel completamente aproveitado, tanto, muitas vezes, pela inaptidão e falta de manejo dos profissionais em executa-las, quando pela inexistência de acesso em um quinto dos lares mineiros. Desta forma, há uma grande brecha relacionada a uma parte considerável dos alunos, que necessitam igualmente, senão mais, desse acompanhamento. 


\section{REFERÊNCIAS}

BARRETO, A. C. F.; ROCHA, D. S.. COVID 19 e educação: resistências, desafios e (im)possibilidades. Revista Encantar: Educação, Cultura e Sociedade, v.2, p.01-11, 2020.

BRASIL. Comitê de Ética em Pesquisa. Comissão Nacional de Ética em Pesquisa. Resolução n. 510, de 07 de abril de 2016. Brasília: CNS, 2016.

BRASIL. Ministério da Educação. CNE aprova diretrizes para escolas durante a pandemia. Brasília: MEC, 2020.

BRASIL. Secretaria de Estado de Educação. Resolução SEE N4.310/2020. Belo Horizonte: SEE, 2020b.

COUTINHO, A. S.; CÔCO, V.. Educação Infantil, políticas governamentais e mobilizações em tempos de pandemia. Práxis Educativa, v.15, n.2016266, p.1-15, 2020.

CURY, C. R. J.. Educação escolar e pandemia. Pedagogia em Ação, v.13, n.1, 2020.

IBGE. Instituto Brasileiro de Geografia e Estatística. Pesquisa Nacional por Amostra de Domicílios Contínua (PNAD). Brasília: IBGE, 2018.

INEP. Instituto Nacional de Estudos e Pesquisas Educacionais Anísio Teixeira. Sinopse Estatística da Educação Básica 2019. Brasília: INEP, 2020.

JHU. John Hopkins University. COVID-19 Dashboard. Center for Systems Science and Engineering, 2020.

LORZING, R. M. S.; NEGRÃO, V. A. M.. Pedagogia e pedagogos da educação infantil em tempos remotos. Pedagogia em Ação, v.13, n.1, 2020.
MCINTOSH, K.. Coronavirus disease 2019 (COVID-19): Epidemiology, virology e prevention. Uptodate, 2020.

MINAS GERAIS. Decreto n. 113, de 12 de março de 2020. Declara situação de emergência no estado em decorrência da pandemia do coronavírus. Belo Horizonte: Governo do Estado de Minas Gerais, 2020.

OLIVEIRA, A. C.; DUARTE, E.; FRANÇA, G. V. A.; GARCIA, L. P. Como o Brasil pode deter a COVID-19. Epidemiol. Serv. Saúde, n.29, v.2, 2020.

REANP. Secretaria de Educação de Minas Gerais. Regime especial de atividades não presenciais. Belo Horizonte: REANP, 2020.

RESENDE, N. S.; MELO, P. E.. Diálogos sobre a escola em contexto de pandemia: contribuições do pensamento de Paulo Freire e do Construcionismo Social. Pedagogia em Ação, v.13, n.1, 2020.

RIBEIRO, M. P.; CLÍMACO, F. C.. Impactos da pandemia na educação infantil: a pandemia acelerou a necessidade de se problematizar a questão digital na educação infantil. Pedagogia em Ação, v.13, n.1, 2020.

RODRIGUES, M. S.. Relações entre produtos audiovisuais e educação: mídia e ensino durante a pandemia de Covid-19. Monografia (Bacharelado em Comunicação Social -

Audiovisual) - Universidade Federal do Rio Grande do Norte, Natal, 2020.

WHO. World Health Organization. Statement on the second meeting of the international health regulations (2005) emergency committee regarding the outbreak of novel coronavirus (2019-nCoV). Geneva: WHO, 2020.

A CBPC - Companhia Brasileira de Produção Científica (CNPJ: 11.221.422/0001-03) detém os direitos materiais desta publicação. Os direitos referem-se à publicação do trabalho em qualquer parte do mundo, incluindo os direitos às renovações, expansões e disseminações da contribuição, bem como outros direitos subsidiários. Todos os trabalhos publicados eletronicamente poderão posteriormente ser publicados em coletâneas impressas sob coordenação da Cognitionis Publishing, da Companhia Brasileira de Produção Científica e seus parceiros autorizados. Os (as) autores (as) preservam os direitos autorais, mas não têm permissão para a publicação da contribuição em outro meio, impresso ou digital, em português ou em tradução. 